\title{
Meningkatkan pengetahuan dan kemampuan kader kesehatan melalui pelatihan bantuan hidup dasar
}

\author{
Santi Herlina (D) *, Wiwin Winarti, Chandra Tri Wahyudi \\ Fakultas IImu Kesehatan, Universitas Pembangunan Nasional Veteran Jakarta \\ *santiherlina@upnvi.ac.id
}

\begin{abstract}
Depok City has status as RW Siaga which has been upgraded to RW Siaga Aktif. So that the community, especially health cadres involved in it, are more active in preventing and managing diseases within the community. The government's efforts to reduce mortality are one of forming health cadres in each region. Health cadres have the role in assisting health workers in day-to-day health emergency response. Therefore, basic community-based life assistance training needs to be developed. The purpose of this community service activity is to increase the knowledge and skills of the Limo City Depok health cadre about providing basic life support in emergency conditions within the community so that first aid can be given before the patient taken to the hospital. The method of carrying out activities is training health cadres on basic life support and preparing the modules of basic life support which can later be the guide for health cadres. The result of this activity is that the increasing independence of the community in the health sector with the results of basic life support knowledge increased to $53 \%$, and $80 \%$ of health cadres were able to carry out basic life support skills.
\end{abstract}

\begin{abstract}
Abstrak Kota Depok memiliki status wilayah sebagai status RW Siaga yang telah ditingkatkan menjadi RW Siaga Aktif, hal ini agar masyarakat terutama kader kesehatan yang terlibat didalamnya lebih aktif pada pencegahan dan penanganan penyakit di masyarakat. Upaya pemerintah dalam menekan angka kematian salah satunya membentuk kader kesehatan di setiap wilayah atau RT. Kader kesehatan memiliki peran membantu petugas kesehatan dalam penanggulangan kegawatdaruratan kesehatan sehari-hari. Oleh sebab itu, pelatihan pemberian pertolongan bantuan hidup dasar berbasis masyarakat perlu dikembangkan. Tujuan dari kegiatan pengabdian masyarakat ini adalah meningkatkan pengetahuan dan keterampilan kader kesehatan Kelurahan Limo Kota Depok tentang pemberian bantuan hidup dasar pada kondisi kegawatdaruratan sehingga pertolongan pertama dapat diberikan sebelum pasien dibawa ke rumah sakit. Metode pelaksanaan kegiatan adalah melatih kader kesehatan tentang pemberian bantuan hidup dasar, dan penyusunan modul bantuan hidup dasar yang nantinya dapat menjadi panduan bagi kader kesehatan. Hasil dari kegiatan ini adalah meningkatnya kemandirian masyarakat dalam bidang kesehatan dengan hasil pengetahuan bantuan hidup dasar menjadi 53\%, dan $80 \%$ kader kesehatan mampu melakukan keterampilan bantuan hidup dasar.
\end{abstract}

Keywords: emergency; health cadre; basic life support

\section{○ OPEN ACCESS}

Citation: Herlina, S., W. Winarti, dan C.T. Wahyudi. 2018. Meningkatkan pengetahuan dan kemampuan kader kesehatan melalui pelatihan bantuan hidup dasar. Riau Journal of Empowerment 1(2): 85-90

https://doi.org/10.31258/raje.1.2.11

Received: 2018-11-11, Revised: 2018-12-18, Accepted: $2018-12-26$

Language: Bahasa Indonesia (id)

(c) 2018 Herlina et al. The article by Author(s) is licensed under a Creative Commons Attribution 4.0 International License. This license permits unrestricted use, distribution, and reproduction in any medium, provided the original author and source are credited. 


\section{PENDAHULUAN}

Gambaran Penyakit tidak menular di Kota Depok yang beresiko mengalami kegawatdaruratan diantaranya adalah hipertensi primer $(53,9 \%)$, diabetes melitus $(11,6 \%)$, dan gagal jantung $(1,17 \%)$. Pada wilayah kota Depok di Kecamatan Limo angka kematian pada tahun 2010 untuk ibu hamil (1769), bayi (39.604), bayi (18.869), balita (146.201), dan usia lanjut (114.060) (Profil Kesehatan Kota Depok, 2010). Pelayanan Kesehatan untuk usia lanjut 60 tahun keatas di wilayah Kecamatan Limo, menempati urutan pertama sebesar 54,6\% (Dinas Kesehatan Kota Depok, 2013).

Kematian terjadi biasanya karena ketidakmampuan orang disekitar untuk menangani penderita pada fase gawat darurat ( golden period). Ketidakmampuan tersebut bisa disebabkan oleh tingkat keparahan, kurang memadainya peralatan, belum adanya sistem yang terpadu dan pengetahuan dalam penanggulangan darurat yang masih kurang, pertolongan yang tepat dalam menangani kasus kegawatdaruratan adalah Basic Life Support (Bantuan Hidup Dasar).

Salah satu upaya dalam meningkatkan harapan hidup penderita adalah melakukan pertolongan pertama. Pertolongan pertama itu sendiri hanya memberikan perawatan yang diperlukan sementara, sambil menunggu petugas kesehatan terlatih datang atau sebelum korban dibawa ke rumah sakit. Bantuan Hidup Dasar (BHD) dapat diajarkan kepada siapa saja. Setiap orang dewasa seharusnya memiliki keterampilan BHD, bahkan anak-anak juga dapat diajarkan sesuai dengan kapasitasnya. Semua lapisan masyarakat seharusnya diajarkan tentang bantuan hidup dasar (Resuscitation Council (UK), 2010).

Gambaran penyakit tidak menular di Kota Depok yang beresiko mengalami kegawatdaruratan diantaranya adalah hipertensi primer $(65,7 \%)$, stroke hemoragik (12\%), gagal jantung (10\%) (Dinas Kesehatan Kota Depok, 2016). Pada wilayah kota Depok di Kecamatan Limo angka kematian pada tahun 2010 untuk ibu hamil (1.769), bayi (39.604), bayi (18.869), balita (146.201), usia lanjut (114.060) (Dinas Kesehatan Kota Depok, 2010). Pelayanan Kesehatan untuk usia lanjut 60 tahun keatas diwilayah Kecamatan Limo, menempati urutan pertama sebesar 54,6\% (Dinas Kesehatan Kota Depok, 2013).

Pada Kota Depok, status RW Siaga juga telah ditingkatkan menjadi RW Siaga Aktif, hal ini agar kader yang terlibat di dalamnya lebih aktif lagi dalam kegawatdaruratan (Departemen Kesehatan Republik Indonesia, 2009). Pada tahun 2009, telah terbentuk sebanyak 836 RW Siaga dengan kelembagaan pokjatap siaga yang ada pada saat ini adalah satgas Kecamatan Siaga, dan 63 satgas Kelurahan Siaga. Kelembagaan lain yang ada yaitu Tim Teknis Siaga dan Forum Fasilitator Siaga. Kelurahan Limo terdiri dari 16 RW yang disetiap RW memiliki 5-10 kader kesehatan baik pada kader posyandu maupun posbindu.

Berdasarkan latar belakang tersebut maka perlu dilakukan tindakan dalam menanggulangi kondisi darurat di tingkat masyarakat dengan pemberian pelatihan bantuan hidup dasar pada kader kesehatan. Tujuan dari kegiatan pengabdian masyarakat ini adalah adanya peningkatan pengetahuan dan keterampilan kader kesehatan Kelurahan Limo Kota Depok tentang pemberian bantuan hidup dasar pada kondisi kegawatdaruratan di masyarakat sehingga pertolongan pertama dapat diberikan sebelum pasien dibawa ke rumah sakit.

\section{METODE PENERAPAN}

Berdasarkan permasalahan yang dihadapi mitra terhadap pelayanan kesehatan pada masyarakat terkait kondisi darurat, maka solusi yang ditawarkan adalah:

1. Pemberian edukasi terkait pemberian bantuan hidup dasar. Edukasi diberikan kepada kader kesehatan untuk menambah pemahaman para kader terkait tindakan apa yang harus diberikan ketika menemukan masyarakat yang mengalami henti nafas atau henti jantung.

2. Pelatihan pemberian bantuan hidup dasar menggunakan phantom simulator dengan mengacu pada American Heart Association (2015) dan Basic Life Support (American Red Cross, 2015; Hazinski et al., 2015). Simulasi pemberian bantuan hidup dasar diberikan dengan menggunakan phantom manusia yang dibuat mirip seperti kondisi manusia yang akan digunakan dalam memberikan bantuan hidup dasar dalam pemberian kompresi, ventilasi atau breathing. 
3. Modul panduan pemberian bantuan hidup dasar berisikan panduan dalam memberikan bantuan hidup dasar disertai dengan langkah-langkah dan gambar-gambar agar memudahkan peserta untuk me-review kembali materi yang sudah didapat bagaimana cara memberikan pertolongan pada kondisi nyata.

\section{HASIL DAN PEMBAHASAN}

Hasil pengabdian ini didapatkan pada karakteristik responden berupa umur, jenis kelamin, dan pendidikan seperti tertera pada Tabel 1.

Table 1. Distribusi Karakteristik Kader Kesehatan Berdasarkan Usia Tahun $2018(n=15)$

\begin{tabular}{ccccc}
\hline Variabel & Mean & SD & Min-Max & $95 \%$ CI \\
\hline Umur & 53,2 & 6,16 & $40-66$ & $49,78-56,61$ \\
\hline
\end{tabular}

Berdasarkan Tabel 1 menunjukkan bahwa kader kesehatan di Kelurahan Limo pada dua RW yaitu RW 03 dan RW 04 rata rata berusia 53 tahun dengan usia termuda adalah 40 tahun, dan usia tertua adalah 66 tahun.

Tabel 2. Distribusi Karakteristik Kader Kesehatan Berdasarkan Jenis kelamin dan Pendidikan Tahun $2018(n=15)$

\begin{tabular}{ccc}
\hline Variabel & $\mathrm{N}$ & $\%$ \\
\hline Jenis Kelamin & & \\
Perempuan & 15 & 100,0 \\
\hline Pendidikan & & 13,3 \\
a. SD & 2 & 46,7 \\
b. SMP & 7 & 33,3 \\
c. SMA & 5 & 6,7 \\
d. PT & 1 & \\
\hline
\end{tabular}

Tabel 2 menunjukan bahwa kader kesehatan di Kelurahan Limo Kota Depok di RW 03 dan RW 04 semuanya adalah perempuan. Rata-rata pendidikan terbanyak adalah SMP.

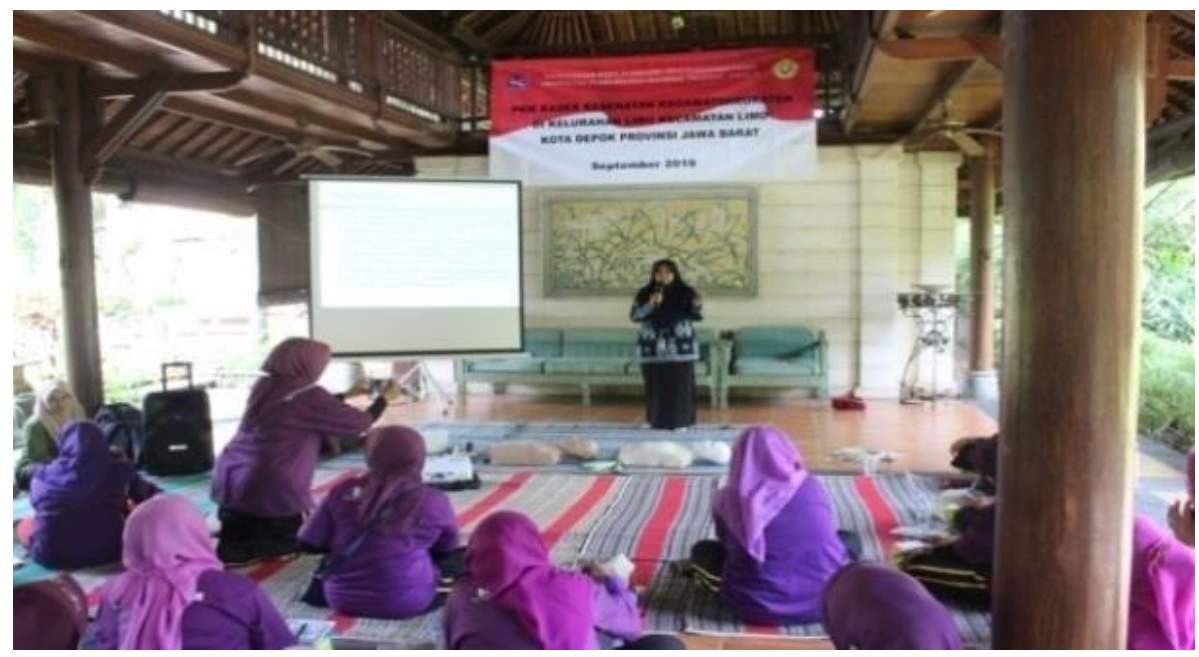

Gambar 1. Pemberian materi tentang bantuan hidup dasar

Capaian yang diharapkan dari kegiatan ini adalah meningkatkan pemahaman kader kesehatan tentang pemberian pertolongan pada kondisi masyarakat yang memiliki keadaan 
gawat darurat seperti henti jantung dan henti nafas. Pemberian materi tentang Bantuan hidup Dasar dapat dilihat pada Gambar 1 dan 2.

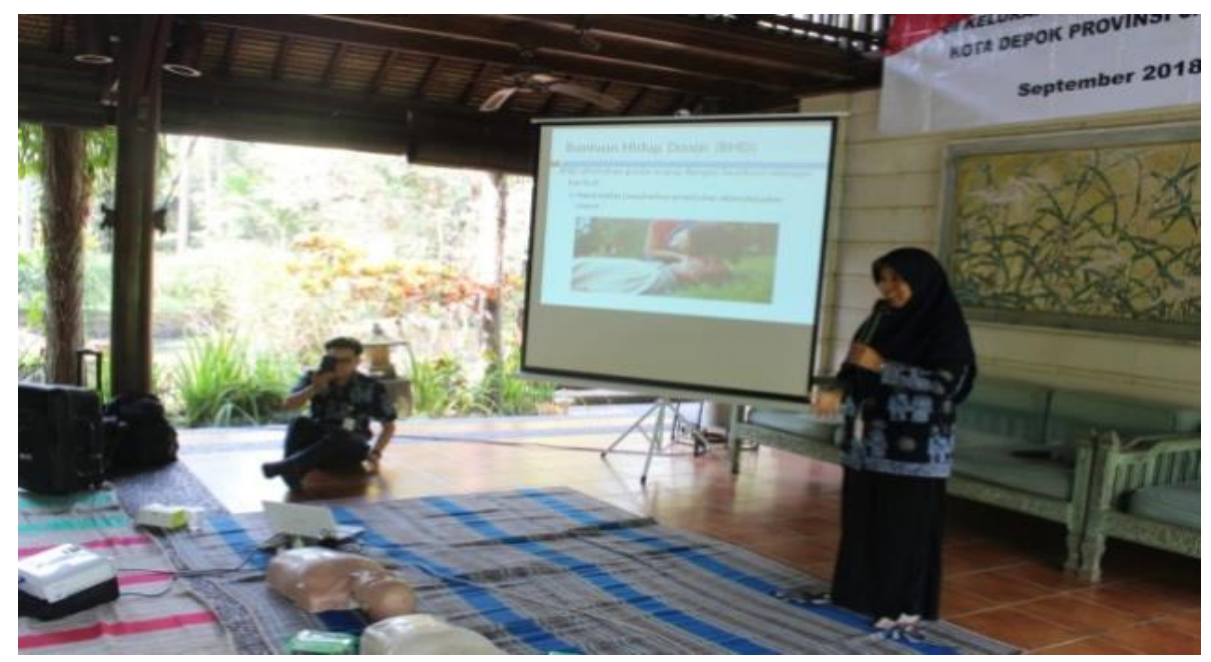

Gambar 2. Pemberian materi tentang bantuan hidup dasar



Gambar 3. Simulasi pemberikan bantuan hidup dasar menggunakan phantom

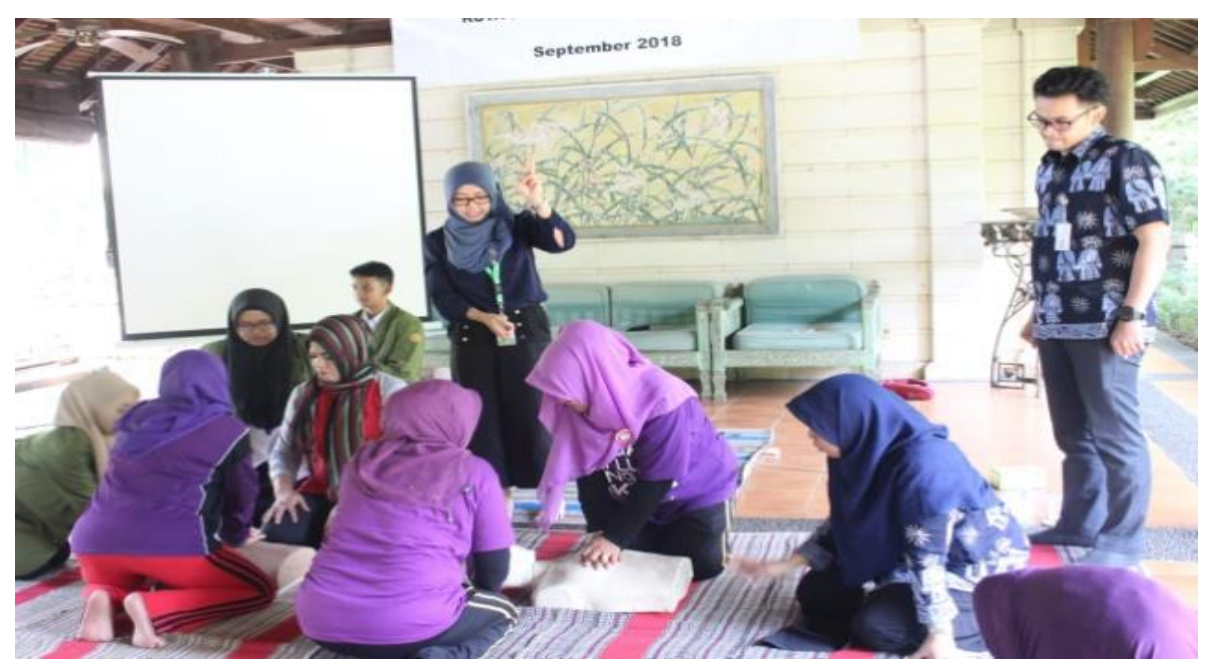

Gambar 4. Penilaian kemampuan peserta melakukan pemberian bantuan hidup dasar 
Selain itu kader kesehatan juga diberikan pelatihan bantuan hidup dasar sehingga para kader telah memiliki kemampuan melakukan bantuan hidup dasar di Kelurahan Limo Kota Depok dengan dikoordinasi oleh Ketua Posbindu dan Kepala Kelurahan Limo. Pelatihan ini menggunakan phantom manusia yang dibuat mirip dengan kondisi manusia yang akan diberikan bantuan hidup dasar. Setiap peserta mencoba satu persatu dan akan dinilai kemampuannya. Kegiatan tersebut dapat dilihat pada Gambar 3 dan 4.

Setelah diberikan pelatihan bantuan hidup dasar terlihat terdapat peningkatan pengetahuan kader kesehatan dan kemampuan dalam memberikan bantuan hidup dasar. Hal tersebut dapat dilihat pada Tabel 3 dan 4. Pada table tersebut terlihat bahwa pengetahuan kader kesehatan mengalami peningkatan menjadi 53,3\% dan kemampuan dalam memberikan tindakan bantuan hidup dasar cukup tinggi sebesar $80 \%$.

Tabel 3. Distribusi pengetahuan kader kesehatan tahun 2018 ( $n=15)$

\begin{tabular}{ccccc}
\hline Variabel & \multicolumn{2}{c}{ Pre } & \multicolumn{2}{c}{ Post } \\
\hline & $\mathrm{n}$ & $\%$ & $\mathrm{n}$ & $\%$ \\
\hline Pengetahuan & & & & \\
a. Tinggi & 7 & 46,7 & 8 & 53,3 \\
b. Rendah & 8 & 53,3 & 7 & 46,7 \\
\hline Total & 15 & 100,0 & 15 & 100,0 \\
\hline
\end{tabular}

Tabel 4. Distribusi kemampuan kader kesehatanTahun $2018(\mathrm{n}=15)$

\begin{tabular}{lcc}
\hline Variabel & $\mathrm{n}$ & $\%$ \\
\hline Kemampuan skill & & \\
a. Mampu & 12 & 80,0 \\
b. Kurang Mampu & 3 & 20,0 \\
\hline Total & 15 & 100,0 \\
\hline
\end{tabular}

Kegiatan ini sangat dirasakan manfaatnya oleh kader kesehatan di Kelurahan Limo Kota Depok sehingga pertologan pertama dapat diberikan dengan memanfaatkan golden period pada masyarakat yang mengalami kondisi henti nafas dan henti jantung. Kegiatan ini pun sangat didukung oleh pihak Kelurahan Limo Kota Depok sehingga program ini sangat cepat direspon untuk menambah keahlian kader yang berada di wilayah tersebut.

\section{KESIMPULAN}

Kesimpulan dari hasil pengabdian ini adalah dihasilkannya modul panduan pemberian bantuan hidup dasar bagi kader kesehatan, dilaksanakan pelatihan pemberian bantuan hidup dasar untuk kader kesehatan, dilaksanakan simulasi kader kesehatan memberikan bantuan hidup dasar. Semua kegiatan tersebut mengakibatkan bertambahnya pengetahuan dan keterampilan kader kesehatan dalam memberikan bantuan hidup dasar.

Sasaran utama dari kegiatan ini adalah meningkatkan kemandirian masyarakat dalam bidang kesehatan sehingga masyarakat dapat memberikan andil dalam meningkatkan derajat kesehatan dan diharapkan dapat menekan angka kematian. Karena ini adalah pengetahuan dan keterampilan maka diperlukan pendampingan berkelanjutan sehingga apa yang sudah diberikan dapat dievaluasi berkala. 


\section{Daftar Pustaka}

1. American Heart Association. 2015. Highlights of the 2015 American Heart Association: Guideline update for CPR and ECC. https://eccguidelines.heart.org/wpcontent/uploads/2015/10/2015-AHA-Guidelines-Highlights-English.pdf. Diakses pada 15 April 2018.

2. American Red Cross. 2015. Basic Life Support for Healthcare Providers: Performance CPR training. United States of America: StayWell.

3. Departemen Kesehatan Republik Indonesia. 2009. Buku Paket Pelatihan Kader Kesehatan dan Tokoh Masyarakat dalam Pengembangan Desa Siaga. Jakarta: Departemen Kesehatan Republik Indonesia.

4. Dinas Kesehatan Kota Depok. 2010. Profil Kesehatan Kota Depok Tahun 2010. Depok: Dinas Kesehatan Kota Depok.

5. Dinas Kesehatan Kota Depok. 2013. Profil Kesehatan Kota Depok Tahun 2013. Depok: Dinas Kesehatan Kota Depok.

6. Dinas Kesehatan Kota Depok. 2016. Profil Kesehatan Kota depok Tahun 2015. Depok: Dinas Kesehatan Kota Depok.

7. Hazinski, M.F.et al. 2015. Part 1: Executive Summary. Circulation, 132(16 suppl 1): S2-S39. https://doi.org/10.1161/CIR.0000000000000270

8. Resuscitation Council (UK). 2010. Resuscitation Guidelines 2010 (October):15-28. London: Resuscitation Council (UK). 